Lisbon - Malacca Port Cities Twin Conferences 2019 / 2020

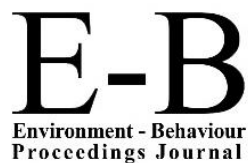

$$
\text { AicQoL2020Malacca }
$$

ASLI (Annual Serial Landmark International) Conferences on QoL2020

https://www.amerabra.org; https://fspu.uitm.edu.my/cebs; https://www.emasemasresources.com/

8th AMER International Conference on Quality of Life

Mahkota Hotel Melaka, Malacca, Malaysia, 18-19 Mar 2020

(Due to the Covid-19 lockdown, paper virtually presented on 25 Mar 2020)

\title{
Exploring Neuro-Landscape Theory Interfaced with Pro-Environment Behaviour Theory for Psychological Restoration of Low Income Group
}

\author{
Noriah Othman'1, Mohd Zahid Mohd Salleh², Nurhayati Abdul Malek', Leny Suzana Suddin ${ }^{3}$ \\ ${ }^{1}$ Centre of Studies for Landscape Architecture, Faculty of Architecture, Planning \& Surveying, \\ Universiti Teknologi MARA, Puncak Alam, Selangor, Malaysia \\ 2 Centre of Studies for Postgraduate, Faculty of Architecture, Planning \& Surveying, \\ Universiti Teknologi MARA, Shah Alam, Selangor, Malaysia. \\ 3 Department of Public Health Medicine, Faculty of Medicine, \\ Universiti Teknologi MARA, Sg. Buloh, Selangor, Malaysia
}

noriaho@yahoo.com, mohdzahidsallehphd20@gmail.com, nurhayati.abdmalek@gmail.com, lenysuzana@yahoo.com Tel: $+6019-2616030$

\begin{abstract}
Mental disorder can be overcome through psychological restoration $(\mathrm{PR})$ in urban agglomerations. There is a growing need for restoration in the urban surrounding environment. Despite many studies on nature and PR, hardly any research in neuroscience and urban nature, its relationship with ProEnvironment Behaviour (PEB), and PR for urban low-income groups (B40). Therefore, this paper attempts to explore prospects via the literature overviews. From the significant literature, a conceptual Neuro-Landscape Model and methodological research framework have been developed. In conclusion, this model can be verified further to gain significant evidence for addressing concerns in the well-being of B40 in Malaysia. (100 words)
\end{abstract}

Keywords: Neuro-Landscape (NL), Pro-Environment Behaviour (PEB), Psychological Restoration (PR), Low Income Group (B40)

eISSN: 2398-4287 @ 2020. The Authors. Published for AMER ABRA cE-Bs by e-International Publishing House, Ltd., UK. This is an open access article under the CC BYNC-ND license (http://creativecommons.org/licenses/by-nc-nd/4.0/). Peer-review under responsibility of AMER (Association of Malaysian Environment-Behaviour Researchers), ABRA (Association of Behavioural Researchers on Asians) and cE-Bs (Centre for Environment-Behaviour Studies), Faculty of Architecture, Planning \& Surveying, Universiti Teknologi MARA, Malaysia. DOI: https://doi.org/10.21834/e-bpj.v5i13.2107

\subsection{Introduction}

As highlighted in the Quito Declaration of the New Urban Agenda, the world's urban population is expected to nearly double by 2050 , with cities to be home to almost 70 percent of the world's population by the sunset of the Sustainable Development Goals in 2030 (World Urban Forum, 2018). The New Urban Agenda adopted at the Habitat III cities conference in Quito, in October 2016 has indicated the improvement of human health and well-being as a critical priority to achieve the sustainable development goals (The New Urban Agenda, 2017). To support this agenda, Malaysia has committed to producing healthy and sustainable cities through promoting quality of life by improving well-being for all. This is in line with one of the six strategic trusts which were outlined in the 11th Malaysian Plan. We are aware that urbanization has brought its own set of psychological problems on mental health and well-being. Due to urbanization, there are changes in life events, which have affected the mental health of urbanites, particularly among the low-income group (B40). Mental disorder, a part of mental health, can be overcome through psychological restoration (PR) in urban agglomerations; thus, a growing need for restoration in the urban surrounding. The co-existence between the neuro-science and landscape is known as neuro-landscape $(\mathrm{NL})$. The human brain shows differential activation patterns in response to the landscape and is associated with emotional states based

eISSN: 2398-4287 ( 2020. The Authors. Published for AMER ABRA cE-Bs by e-International Publishing House, Ltd., UK. This is an open access article under the CC BYNC-ND license (http://creativecommons.org/licenses/by-nc-nd/4.0/). Peer-review under responsibility of AMER (Association of Malaysian Environment-Behaviour Researchers), ABRA (Association of Behavioural Researchers on Asians) and cE-Bs (Centre for Environment-Behaviour Studies), Faculty of Architecture, Planning \& Surveying, Universiti Teknologi MARA, Malaysia

DOI: https://doi.org/10.21834/e-bpj.v5i13.2107 
on psychology. Despite many studies on nature and $P R$, hardly any studied in neuroscience and urban nature aspect, its relationship with Pro-Environment Behaviour (PEB) and PR for B40. This paper aims to explore the prospect via literature overviews on various theories that are related to one another into neuroscience, landscape, PEB, which can trigger PR. The main objective of this paper is to develop the potential of PEB integration between NL with a Neuro-Landscape Model for PR among the B40 group. The information gathered will be beneficial to landscape and urban planners to plan for healthier cities in the future, focusing on the underprivileged group. This interdisciplinary research involving neuroscience, landscape, behaviour, and psychology disciplines will be new and innovative research to address concerns in the well-being of B40 in Malaysia. Thus this study is limited to the low-income group in Malaysia that lives in urban cities.

\subsection{Literature Review}

AA psychological disorder, also known as a mental disorder, is a pattern of behavioural or psychological symptoms that impact multiple life areas and create distress for the person experiencing these. Low socioeconomic status is known to be associated with a higher prevalence of major depression, substance abuse, and personality disorders (Helbich 2018; Rathod, 2017). For the problem of mental disorder to be successfully confronted, a broad understanding of poverty, taking into account both individual and contextual factors, is required. In Malaysia, by 2020, mental disorder is expected to be the second biggest health problem affecting Malaysians after heart disease. According to the latest National Health and Morbidity Survey, every three in 10 adults aged 16 years and above in Malaysia suffer from some form of mental health issues (the Sun daily, 18 April 2018). Mental disorder can interfere with an individual's ability to function in multiple social spaces. The burden of having a mental disorder is not only carried by the individual; it is a ripple effect that is felt by the family, the workplace, healthcare systems, the government, other communities and income (Razali, S. et al., 2019; Jenkins et al., 2011). The effects of mental disorder are most adversely felt by the underprivileged, which puts further strain on the government due to loss of productivity and social welfare. Depression alone costs Malaysia RM1.9 billion (Chen, 2017).

The potential for reducing negative psychological states or increasing positive ones is a well-established value present in natural landscapes, known as restorative potential. Various studies have demonstrated that contact with nature can contribute to reduce stress and to promote positive states of mood and adequate cognitive function (attention) (Giusti et al., 2018). These effects, known as restorative effects, have been widely documented in the literature on perception of environmental restoration (Capaldi et al. 2014) and psychological restoration (Douglas et al., 2017). In the urban context, urban green environments, such as parks and urban forests, are elements of the environment that many intuitively consider healthy. Greater surrounding greenness has been linked to improved physical and mental health in all socioeconomic strata and both sexes (Khalid, N. S. et al., 2018; Triguero-Mas et al., 2015). More greenery in the neighbourhood was linked to lower levels of depression, anxiety, and stress (Bratman et al., 2015). However, the possible restorative potential of urban landscapes related to urban nature in Malaysia is less studied despite cities have been considered as being stressful and over-demanding (Adli et al., 2017). Another area of concern is the accessibility of the community to urban nature, which is part of the green space.

According to Hoffimann et al., (2017), green space is not equally available or accessible to all population groups, with low-income communities often having less green space or being exposed to poorly maintained, vandalized or unsafe green areas. Socioeconomic inequalities in access to green space and resulting health benefits may, therefore, contribute to disparities in health. There is evidence that less mobile people (e.g., the elderly and children) with lower household incomes and less education benefit most from contact with nature (Whitburn, 2018). Whitburn (2018) suggested that increasing the level of vegetation, especially in less green neighbourhoods, may have a positive effect on the residents' mental well-being. Therefore, this research is vital to meet the health challenges of contemporary mass urbanization, which will affect the lives of the community, especially for the low-income group. This group is also term as B40 in Malaysia, meaning the bottom 40\% of the income group with monthly income RM3000 and below. About 2.7 million households in Malaysia have been accounted for the welfare aggregate below $40 \%$ in Eleventh Malaysia Plan's growth rate (Economic Planning Unit, 2017). Whereas in the Tenth Malaysia Plan, only 2.4 million households of B40 were reported and to be escalating nearly 300,000 afterward. In fact, $68 \%$ of them are local people (Bumiputeras), and $56 \%$ lived in an urban area (Economic Planning Unit, 2017). Low socioeconomic status is potentially faced with health and insecurity problems that impact their lifestyle. Thus, a progressive and innovative solution needs to find to liberate them from the existing distress situation.

Innovation in environment, behaviour, and psychological research promotes Pro-Environment Behaviour (PEB) and its association with pro-environmental attitudes in psychological context (Giusti et al., 2018). PEB is such behaviour which is generally (or according to the knowledge of environmental science) judged in the context of the considered society as a protective way of environmental behaviour or a tribute to the healthy environment thus PEB consciously seeks to minimise the negative impact of one's actions on the natural or built world (Claudio et al., 2018). Up to date, research has demonstrated a significant relationship between connectedness to nature and pro-environmental behaviour (Pensini et al., 2016; Whitburn et al., 2018). Hartig et al., 2014 stated PEB was influenced both directly and indirectly by restorative experiences in connection nature. These restorative experiences appear to influence the way people think about and value nature, and this, in turn, influences how they treat it (Hartig et al., 2014, Anderson, 2017). Whitburn et al. (2018) also found the positive effect of psychological restoration on PEB was partially mediated by environmental concern. They concluded that exposure to urban nature and tree planting is related to PEB and psychological restoration.

New technologies and developments in cognitive science have lead researchers from various disciplines to use them in their research. Neuroscience and cognitive science are new ways to study people's reactions toward the environment (Banaei et al., 2017; Baymgartner et al., 2019; Mavros et al., 2016). Recent technological advances, especially relatively low-cost electroencephalography (EEG) data acquisition equipment and open-source analytical tools, make possible the adoption of EEG outside the traditional clinical 
or neuroscience context into a new domain of research (Mavros et al. 2016). A recent study by Baymgartner et al., 2019 used EEG to find a trait that explains pro-environmental behaviour. Mavros et al. (2016) use EEG in the study of urban behaviour to unravel the neural processes that enable spatial perception and cognition. Banaei et al. (2015) studied the urban trails using EEG to understand brain activities when the participants strolling on the trails.

\subsection{Methodology}

This study will involve mixed methods, combining the qualitative and quantitative data collection approach, as shown in Fig 1, p.4.

\subsection{Exposure to 'nature' in the urban environment (Stage 1)}

Site inventories and analysis of the study areas will be done based on the checklist consisting of the elements that need to be studied related to 'nature' in the urban area. 'Nature' in this study includes urban forests, public parks, street planting that are accessible to the B40 group. The coverage areas of these green urban spaces and the elements in the green spaces will be determined. Data on urban green spaces such as the urban forest, parks, and street planting will be collected from selected local authorities. Besides that, data on the social and economical of the study area will also be gathered to determine the statistics of the lower-income group lived in the study area. To be more specific, neighbourhood vegetation cover will be used to access participants' exposure to nature. The total area of vegetation coverage will be calculated for each neighbourhood with the intention to categorize the distinct vegetation levels (Whitburn et al., 2018).

\subsection{Depression, Anxiety and Stress (DASS-21) (Stage 2)}

A survey will be administered to find out the emotional states of selective samples among the lower-income group (B40). Sampling will be carried out at the selected areas, and a set of the questionnaire will be answered by the participants with the assistance of the researchers. The formulation of the questionnaire is based on Depression, Anxiety, and Stress (DASS) instrument. The DASS is a 42item self-report instrument designed to measure the three related negative emotional states of depression, anxiety, and tension/stress (Lovibond and Lovibond 1995). The original 42-item DASS of Lovibond was modified into a shorter 21 -item version (Antony et al., 1998). Several studies are published on its reliability and validity worldwide, all showing the DASS-21 is a well-established instrument to measure symptoms of depression, anxiety and stress in both clinical and non-clinical samples of adults (Jun et al., 2018). In DASS-21, each of the emotional states contains seven items. Each item is rated at a 4-point severity/frequency scales to rate the extent to which the participants' experiences. Scores for depression, anxiety, and stress are calculated by summing the scores for the relevant items. For the depression subscales, the scores are categorized as normal (0-4), mild (5-6), moderate (7-10), severe (11-13), and extremely severe (14 and above). Malaysia's study conducted by Yusoff (2013) has shown an acceptable level of internal reliability among the healthy population and clinic outpatients using DASS-21.

\subsection{Pro-Environment Behaviour (PEB) and Psychological Restoration (Stage 2)}

The General Ecological Behaviour Scale (GEBS) (Frick et al., 2004) will be the basis to measure the internal and external stimuli of PEB. It represents a general measure of ecological behaviour and is not restricted to any particular context or culture or category of ecological behaviours. Higher scores indicate greater involvement in ecological behaviour. The latest version of the GEB scale consists of 32 polytomous and 18 dichotomous items (Anderson, 2017). The polytomous items measure the frequency of behaviour on a 5-point scale. The scale ranges from 1 ("Never") to 5 ("Always"). The 18 dichotomous items are "Yes/No" questions that are scored with 1 and 0 , respectively. To fit this study, some adaptation will be made on the GEBS. In response to people's interaction with nature, personal subjective feeling of connectedness to nature will be assessed with the Connectedness to Nature Scale (CNS) (Mayer and Frantz, 2004). The scale is a 14-item questionnaire used to measure the extent to which people feel emotionally connected to the urban natural environment. Responses are rated from $1=$ strongly disagree to $5=$ strongly agree with higher scores indicating a greater feeling of connectedness to nature. Mean ratings from 1 to 5 serve as the measure in the analysis.

\subsection{Semi-Structured Interview (Stage 2)}

Semi-structured face to face interviews will be conducted to allow the participants the opportunity to respond freely and share their opinions and perspectives in relation to nature in the urban context. Volunteered participants will be interviewed. This interview will assist the researchers in gaining information on the connection of PEBs stimuli with psychological restoration. Qualitative semi-structured interviews are one of the most dominant and widely used methods of data collection within the social sciences (Evan, 2017).

\subsection{Neuro-Landscape Brain Activity (Stage 2)}

The co-existence between the neuro-science and landscape is known as neuro-landscape. To measure brain activity patterns on particular landscape stimuli (urban nature), electroencephalography (EEG) will be employed. The brain activation patterns are presumably associated with the personal preference of the scenic views, reflecting a given subject's emotional status and feelings based on psychology. Mavros et al., (2016) stated EEG measures brain function and activity, as well as the responses of the autonomic nervous system (heart rate, skin conductivity, endocrinological levels) as a window to cognitive and mental states or related psychological phenomena or to study the effects of these phenomena on psychology. Through convenience sampling, volunteers from the B40 (40 participants) will be asked to look at video recording (VR) for 5 minutes of urban nature taken in their neighbourhood. EEG device will record the brain functions. The EEG signals will be analyzed using EEGLAB and MATLAB software. Two-channel locations of EEG will 
be studied. The first part is the Beta Band $(18-24 \mathrm{~Hz})$, where changes of this part showing being active, alert, and excited. The second part is the Alpha band $(7-13 \mathrm{~Hz})$, where changes in this part are showing the calmness level. ANOVA test will be done for signifying the data at $P<0.01$.

\subsection{Development of Model (Stage 3)}

Analysis of the effect of nature in the urban setting for the psychological restoration of the B40 will be done using descriptive and inferential statistics. Structural Equation Model (SEM) is chosen because it is a multivariate statistical technique that is suitable to analyse structural relationships between PEBs parameters and psychological parameters of the participants. Besides that, this technique is the combination of factor analysis and multiple regression analysis. Based on these estimated multiple and interrelated dependence in the single analysis, a model of neuro-landscape that looks into PEB and psychological restoration for the B40 group will be constructed.

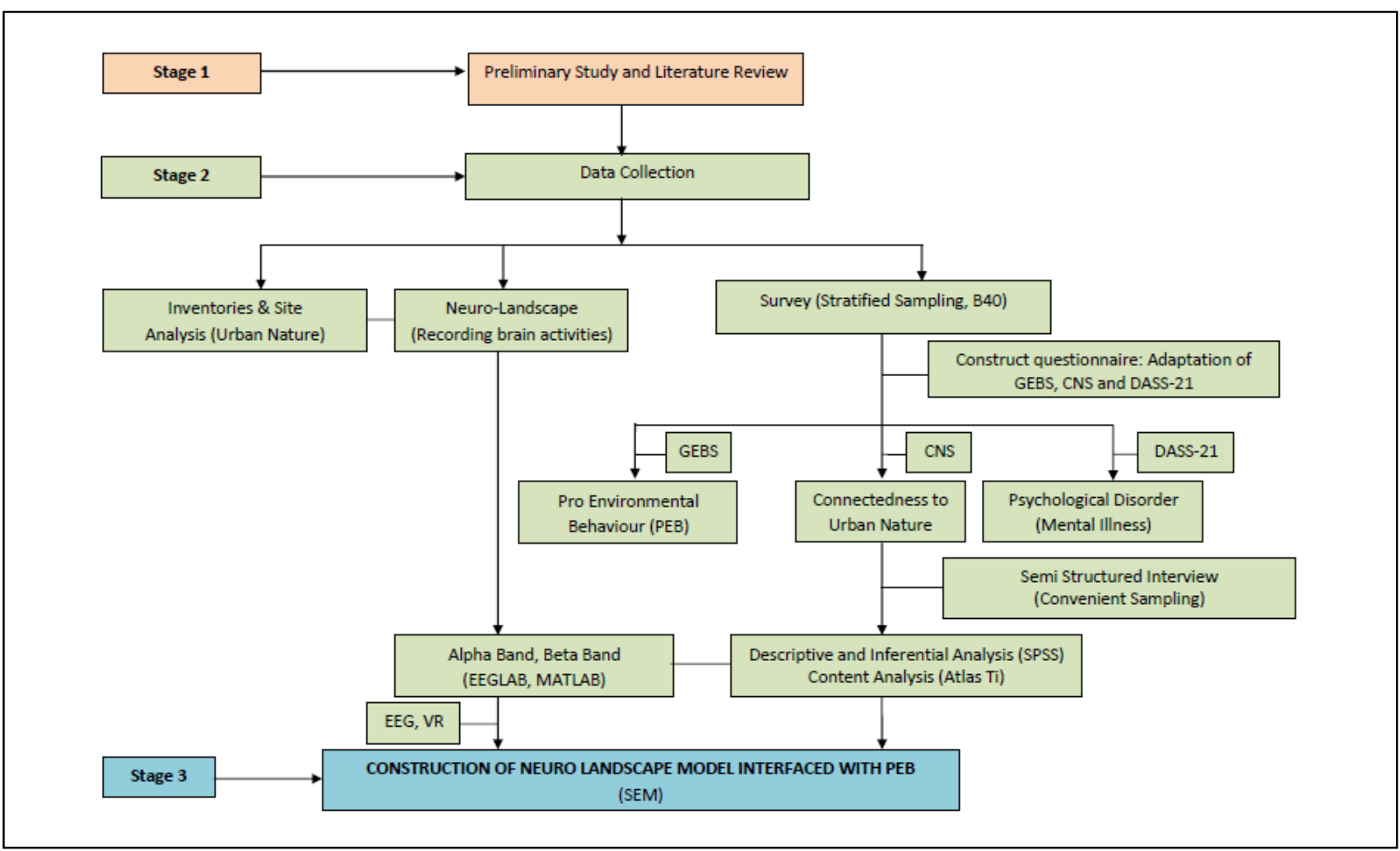

Fig. 1: A Methodological Research Framework

(Source: Author)

\subsection{Findings and Discussion}

This This study has explored the prospect of neuro-landscape and PEB via literature overviews accordingly. The study found that interdisciplinary research involving neuroscience, landscape, behaviour, and psychology disciplines will be new and innovative research to address concerns in the well-being of B40 in Malaysia. Since this study is still at a preliminary stage, the literature reviews and the analysis of various theories help to build the research method that will contribute to new findings in neuro-landscape and psychological restoration. Integrating various theories addressing the issues will show the connectedness of brain functions to landscape stimuli and hope to improve the psychological health of the people. Thus, a methodological research framework (Fig. 1) and a conceptual NeuroLandscape Model (Fig.2) have been developed for future study afterward. The model was derived from the underpinning theories such as the Attention Restoration Theory (ART), Psychological Stress Recovery (PSR), The Pro-Environmental Behaviour Model, and Wellbeing model. Most of the studies have discovered the significant relationship between urban nature (UN) and psychological restoration (PR) by using ART and PSR theories (Mayer \& Frantz, 2004 \& Bratman et al., 2015). While the significant evidence for the UN and PEB was proved by the studies that apply the Pro-Environmental Behaviour Model (Whitburn, J. 2018). However, the significant association between PEB and PR is untapped directly from previous studies. Thus, the study intends to link PEB as a mediator for UNE and PR's relationship for the B40 group of Malaysians, as exhibited in Fig. 2, page 5.

Besides, this study is also in line with scientific and technological progress. Adaptation of EEG in this study may have a positive impact, especially in landscape architecture field research. Previously, most of the study measures human perception alone without considering the emotional status. Somehow, the emotional status of brain activity in-person inconsistent with their perception about somethings as well as external performance. The brain activity will reveal the frequencies and amplitude simultaneously while performing certain activities via visual sensory. The EEG also will evaluate the electromagnetic wave, such as alpha and beta oscillations. Most studies have conducted an experimental approach by using photos and videos of specific areas that have been selected. The on-site 
experiment also has been conducted. There are some considerations that need to be emphasized, such as climate condition, duration of time, and the number of samples. However, those aspects need to be controlled wisely in every single experiment. Therefore, this study may incorporate the EEG to minimise the inconsistency between the internal and external performance of people that views the urban nature. Besides, some control variables also need to be emphasized correctly for minimizing the deficiency during EEG activity.

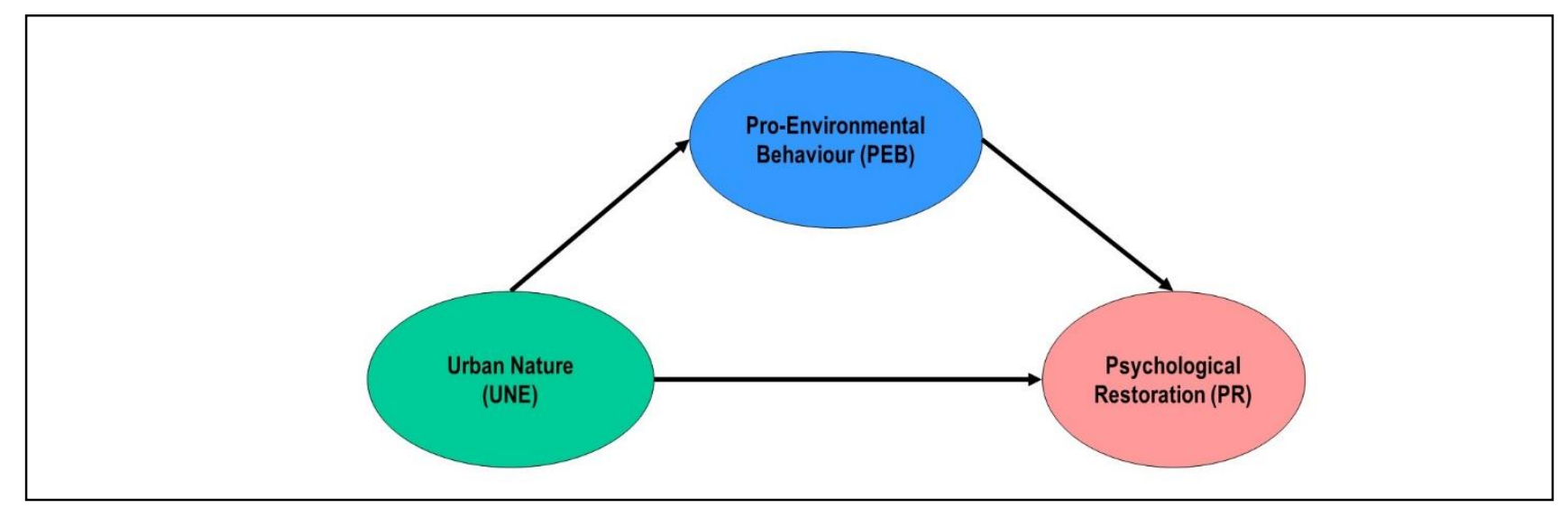

Fig. 2: A Conceptual Neuro-landscape Model

(Source: Author)

\subsection{Conclusion}

The exploration of the literature in this study highlights the significant prospect between neuroscience, landscape, and psychology fields. Although this paper is still at a preliminary stage, a novel of this study has been identified and needs to be proven by the forthcoming study. The significant evidence of this study may transform the low-income group to liberate them from mental disorders via providing vast and conducive green spaces within their neighbourhood. From that, PEB among them might be stimulated directly and simultaneously. However, some aspects need to be emphasized for getting the significant evidence for the study, such as the scope of urban nature, characteristics of the study area, sampling technique, and EEG tool availability and application. In conclusion, this study will be a stepping stone for the future landscape planning which will involve urban nature for the benefit of the low-income group.

\section{Acknowledgements}

The authors wish to thank Faculty of Architecture, Planning and Surveying, Universiti Teknologi MARA (UiTM) and Research Management Institute (RMI) for permission to conduct the research. Financial assistance for this research is funded by Minister of Higher Education (MOHE) under Fundamental Research Grant Scheme (FRGS) (600-IRMI/FRGS 5/3 (312/2019).

\section{References}

Adli. M., Merger, M. \& Brakemeir, E.L (2017). Neurourbanism: towards a new discipline. The Lancet Psychiatry, 4(3):183-185. American Psychiatric Association's diagnostic manual, the DSM-5, 2013

Andersen, J. (2017). Minding the Gap between Awareness and Behavior: Roles of Mindfulness and Connectedness to Nature in Fostering Ecological Behavior. Master's thesis, Harvard Extension School. http://nrs.harvard.edu/urn-3:HUL.InstRepos:33826274

Antony, M.M., Bieling, P.J., Cox, B.J., Enns, M.W., \& Swinson, R.P. (1998) Psychometric properties of the 42-item and 21-item versions of the depression anxiety stress scales in clinical groups and a community sample. Psychological Assessment, 10:176-181.

Banaei, M, Hatami, J., Yazdanfar, A. \& Klaus Gramann (2017). Walking through Architectural Spaces: The Impact of Interior Forms on Human Brain Dynamics. Front Hum Neurosci. 11: 477.doi: 10.3389/fnhum.2017.00477

Baumgartner, T., Langenbach B.P., Giannotti, L.R.R., Müri, R.M. \& Knoch, D. (2019). Frequency of Everyday Pro-Environmental Behaviour is Explained by Baseline Activation in Lateral Prefrontal Cortex. Sci Rep. Jan 9, 9(1): 9. doi: 10.1038/s41598-018-36956-2.

Bratman GN, Hamilton JP, Hahn KS, Daily GC \& Gross JJ (2015) Nature experience reduces rumination and sub-genial prefrontal cortex activation. Proc Natl Acad Sci U S A. 112: $8567-8572$

Capaldi, C.A.,, Dopko, R.L. \& Zelenski (2014). The relationship between nature connectedness and happiness: a meta-analysis. Front. Psychol., 08 September 2014. https://doi.org/10.3389/fpsyg.2014.00976

Chen, (2017). http://www.wongchen.com/wp-content/uploads/2017/08/Doubly-Disadvantaged-Investigating-Mental-Health-and-Poverty.pdf

Douglas, O., Lennon, M. \& Scott, M. (2017). Green space benefits for health and well-being: Alife-course approach for Urban Planning, Design and Management. Cities, 66:53-62 
Economic Planning Unit, EPU (2017). Eleventh Malaysian Plan: improving well- being for all. Available from: http://www.epu.gov.my/en/rmk/eleventh- malaysia-plan2016-2020. Accessed 10 Apr 2017.

Evan, C. (2017). Analysing Semi-Structured Interviews Using Thematic Analysis: Exploring Voluntary Civic Participation among Adults. Sage Publications. doi: http://dx.doi.org/10.4135/9781526439284

Frick, J., Kaiser, F.G., \& Wilson, M. (2004) Environmental knowledge and observation behaviour: Exploring prevalence and structure in a representative sample. Personality and Individual Differences, 37:1597-1613.

Giusti, M., Svane, U., Raymond, C. M., \& Beery, T. H. (2018). A framework to assess where and how children connect to nature. Front. Psychol. 8:2283. doi: 10.3389/fpsyg.2017.02283

Hartig, T., \& Staats, H. (2006) The need for psychological restoration as a determinant of environmental preference. Journal of EnvironmentPsychology, 26(3): 215-226.

Helbich, M. (2018). Mental Health and Environmental Exposure: An Editorial. Int J Environ Res Public Health. 2018 Oct; 15(10): 2207. Published online 2018 Oct 10. doi: 10.3390/ijerph15102207.

Hoffimann, E., Henrique Barros \& Ana Isabel Ribeiro (2017). Socioeconomic Inequalities in Green Space Quality and Accessibility Evidence from a Southern European City. Int J Environ Res Public Health. Aug; 14(8): 916. Published online 2017 Aug 15. doi:10.3390/ijerph14080916

Jenkins, R., Baingana, F., Ahmad, R. \& McDaid, D. (2011). Social, Economic, Human Rights and Political Challenges to Global Mental Health. Mental Health in Family Medicine, vol. 8, no. 2, 2011, pp. 87-96, https://www.ncbi.nlm.nih.gov/pmc/articles/PMC3178190/

Jun, D., Johnston, V., Kim, J. M., \& O'Leary, S. (2018). Cross-cultural adaptation and validation of the Depression, Anxiety and Stress Scale-21 (DASS-21) in the Korean working population. Work, 59(1):93-102.

Khalid, N. S., Baba, N. F., \& Hamdan, H. (2018). Improving Quality of Life through Recreational Behaviour in Urban Park. Asian Journal of Quality of Life, 3(13): 80-88.

Lovibond, P.F. \& Lovibond, S.H. (1995). The structure of negative emotional states: Comparison of the Depression Anxiety Stress Scales (DASS) with the Beck Depression and Anxiety Inventories. Behaviour Research and Therapy, 33:335-343.

Mayer, F. S., \& Frantz, C. M. (2004). The connectedness to nature scale: A measure of individuals' feeling in community with nature. Journal of Environmental Psychology, 24(4):503-515. doi: 10.1016/j.jenvp.2004.10.001

Mavros, P., Austwick, M.Z. \& Smith, A. (2016). Geo-EEG: Towards the Use of EEG in the Study of Urban Behaviour. Appl. Spatial Analysis and Policy. 9 (2):191-212. DOI: $10.1007 / \mathrm{s} 12061-015-9181-z$

Pensini, P., Horn, E., \& Caltabiano, N. J. (2016). An exploration of the relationships between adults' childhood and current nature exposure and their mental well-being. Child. Youth Environ. 26:125-147. doi: 10.7721/chilyoutenvi.26.1.0125

Rathod S, Pinniti N, Irfan M, Gorczynski P, Rathod P, \& Gega L. (2017) Mental Health Service Provision in Low-and Middle-Income Countries. Health Services Insights. $2017 ; 10$

Razali, S., Yung-An, C., Nazali, M. I. M., \& Nawawi, H. M. (2019). Determining Predictors of Depression and Anxiety for Prevention of Common Mental Illness among Staff of an Academic Institution in Malaysia. Asian Journal of Quality of Life, 4(17):1-13.

The New Urban Agenda (2017). http://habitat3.org/wp-content/uploads/NUA-English-With-Index-1.pdf

The Sun Daily (18 Apr 2018). Resolving mental illness issues in Malaysia. https://www.thesundaily.my/archive/resolving-mental-illness-issues-malaysia-YUARCH541062

Triguero-Mas M, Dadvand P, Cirach M, Martínez D, Medina A, Mompart A, Basagaña X, Gražulevičienè R, \& Nieuwenhuijsen MJ (2015) Natural outdoor environments and mental and physical health: relationships and mechanisms. Environ Int 77,35-41

Whitburn, J., Linklater, W. L., \& Milfont, T. L. (2018). Exposure to urban nature and tree planting are related to pro-environmental behavior via connection to nature, the use of nature for psychological restoration, and environmental attitudes. Environment and Behavior, 1-24.

World Urban Forum, WUF 9 (2018) Kuala Lumpur, 7-13 Feb 2018. Cities 2030, Cities for All: Implementing the New Urban Agenda. Concept paper, UN-Habitat.

Yusoff, M.S.B. (2013) Psychometric properties of the Depression Anxiety Stress Scale in a sample of medical degree applicants. International Medical Journal (Tokyo), 20(30):295-300. 